\title{
Investigation of the photo-catalytic coating on AZ91 alloy
}

\author{
Jian-Yih Wang ${ }^{\mathrm{a}, *}$, Hao-Jan Tsai ${ }^{\mathrm{a}}$, Jun-Yen Uan ${ }^{\mathrm{b}}$, \\ Ming-Show Wong ${ }^{\mathrm{a}}$, Shyi-Kaan $\mathrm{Wu}^{\mathrm{c}}$ \\ ${ }^{a}$ Department of Material Science and Engineering, National Dong Hwa University, No. 1, Sec. 2, Da-Hsueh Road, \\ Shoufeng, Hualien County 974, Taiwan \\ ${ }^{\mathrm{b}}$ Department of Material Science and Engineering, National Chung Hsing University, 250 Kuo Kuang Road, \\ Taichung 402, Taiwan \\ ${ }^{c}$ Department of Materials Science and Engineering, National Taiwan University, No. 1, Sec. 4, Roosevelt Road, \\ Taipei, 106 Taiwan
}

Received 14 June 2007; received in revised form 12 December 2007; accepted 12 December 2007

\begin{abstract}
$\mathrm{A} \mathrm{TiO}_{2}$ thin film was deposited on AZ91 alloy to enhance the corrosion-resistance and photo-catalytic properties. Experimental results showed that the $\mathrm{TiO}_{2}$-coated $\mathrm{AZ91}$ exhibited hydrophilicity. The corrosion potential of $\mathrm{TiO}_{2}$-deposited $\mathrm{AZ91}$ was higher than that of the uncoated AZ91, suggesting an increase in the intrinsic corrosion resistance. Compared with the uncoated samples, the corrosion resistance of $\mathrm{TiO}_{2}$-deposited samples, on the other hand, deteriorated. FE-SEM observation showed polycrystalline characteristics as well as the presence of pinholes on the film. EDS analysis revealed the pinholes to be locales of incomplete deposition, where accelerated corrosion occurred.
\end{abstract}

(C) 2007 Elsevier B.V. All rights reserved.

Keywords: AZ91 alloy; Magnetron sputtering; Contact angle; Corrosion resistance; Photo-catalytic

\section{Introduction}

Magnesium alloys are well known for such outstanding properties as low density, high specific strength, vibration absorption ability, and electromagnetic shielding [1]. Besides their use as $3 \mathrm{C}$ products, magnesium alloys have found many applications in transportation industries. AZ91 (9\% Al-1\% Zn), among all magnesium alloys, is the most widely used because of its good castability and mechanical properties, with especially large demand for the shells of Notepad PC in the future [2].

However, because of the poor corrosion resistance of magnesium alloys, their applications can be severely limited without proper corrosion-prevention treatment [3]. Currently, chemical conversion process followed by painting [4] or anodizing treatment [5] is the most widely used surface treatment, yet the results have not been sufficient. Several researches - including such surface treatment as micro-arc anode oxidation [6,7], new conversion coating [8], and cladding of pure metal elements on the

\footnotetext{
* Corresponding author. Tel.: +886 922 233553; fax: +886 38634200 .

E-mail address: jy-wang@yahoo.com.tw (J.-Y. Wang).
}

surface of magnesium alloys [9-11] - were conducted in industry to address this issue. Among other active research goals are the deposition of layers of AlN + AlN + AlN, or AlN + TiN on magnesium alloys using PVD [12], purification of magnesium alloys, and the effect of second phase [13].

The present study investigates the deposition of $\mathrm{a} \mathrm{TiO}_{2}$ photocatalytic film on AZ91 alloy to improve the corrosion resistance and impart photo-catalytic effect for use in dirt-prevention (self cleaning function), which is a property that can be conveniently assessed by measuring the contact angles as an indication of the thin film's hydrophilicity. The effectiveness of dirt-prevention, and therefore the photocatalytic characteristic, increases with decreasing contact angles. Moreover, the use of $\mathrm{TiO}_{2}$ as a depositing material offers the benefit of shunning environmentally harmful materials that are usually used in conventional surface treatments.

\section{Experimental procedures}

AZ91 billets, $7^{\prime \prime}$ in diameter, were first heated to $350^{\circ} \mathrm{C}$ and then extruded into a sheet metal $100 \mathrm{~mm}$ in thickness. The sheet metal was further hot rolled at $300{ }^{\circ} \mathrm{C}$ to a thickness of $2 \mathrm{~mm}$. Specimens of AZ91, $30 \mathrm{~mm} \times 3 \mathrm{~mm}$, were cut for photo-catalytic deposition. 
A thin film of $\mathrm{TiO}_{2}$ was deposited on the surface of the samples using DC magnetron sputtering under the following sputtering conditions: substrate temperature, $250^{\circ} \mathrm{C}$; voltage, $470 \mathrm{~V}$; vacuum pressure, $2 \mathrm{mTorr}$; argon gas flux, $40 \mathrm{sccm}$; oxygen gas flux, $7 \mathrm{sccm}$. Field emission scanning electron microscopy (FE-SEM, JSM-7000F) and transmission electron microscopy (TEM, JEOL2010) were used to observe the microstructure of the deposited films and AZ91 substrate. The chemical composition of the films and the substrate were analyzed using energy dispersive spectroscopy (EDS).

The crystal structure of the thin film was examined using low angle $\left(1.5^{\circ}\right)$ X-ray diffraction (XRD) with $\mathrm{Cu} \mathrm{K} \alpha(\lambda=0.15406 \mathrm{~nm})$ radiation.

Testing for photo-catalytic characteristics (self-cleaning) was conducted by measuring the contact angles. For contact angle measurement, specimens of AZ91 substrates, both with and without thin film deposition, were exposed to ultraviolet light, and the contact angles of water were measured at an interval of $10 \mathrm{~min}$.

Corrosion test was performed in $\mathrm{NaCl}$ solution with $\mathrm{pH} 7.4$, using a constant potentiometer to measure the potentiodynamic polarization curves of $\mathrm{TiO}_{2}$ deposited and uncoated substrates, respectively. To ensure the reproducibility of the data, a total of two specimens were tested for corrosion resistance. Each test was conducted in a corrosion cell that contained $300 \mathrm{ml}$ of $0.6 \mathrm{M} \mathrm{NaCl}$ solution at room temperature, at a scan rate of $0.5 \mathrm{~m} \mathrm{~V}^{-1}$. All the electrochemical measurements were made using a Princeton Applied Research model $263 \mathrm{~A}$ potentiostat/galvanostat with its M352 software. Platinum gauze was used as a counter electrode, with silver/silver chloride $(\mathrm{Ag} / \mathrm{AgCl})$ as the reference electrode. The Tafel extrapolation method $[14,15]$ was used to determine the corrosion current density $\left(I_{\text {corr }}\right)$. Cathodic polarization data are preferred for this method for its ease of measurement [14].

\section{Results and discussion}

\subsection{Crystal structure of photo-catalytic thin films}

Of the three possible crystal morphologies of $\mathrm{TiO}_{2}$-rutile, anatase, and brookite-anatase shows the strongest photocatalytic properties [16]. Fig. 1 shows the low angle XRD spectrum for the deposited film. The distinct crystalline Anatase phase with photo-catalytic characteristics can be identified from the spectrum. Also present in the spectrum are Mg-peaks, which appeared because of X-ray penetration of the thin film into the substrate, exciting diffraction peaks from AZ91 Mg-substrate.

\subsection{Contact angle variations}

When a photo-catalytic $\mathrm{TiO}_{2}$ is exposed to UV light, it forms a hydrophilic surface [17]. Fig. 2 shows the contact angle vari-

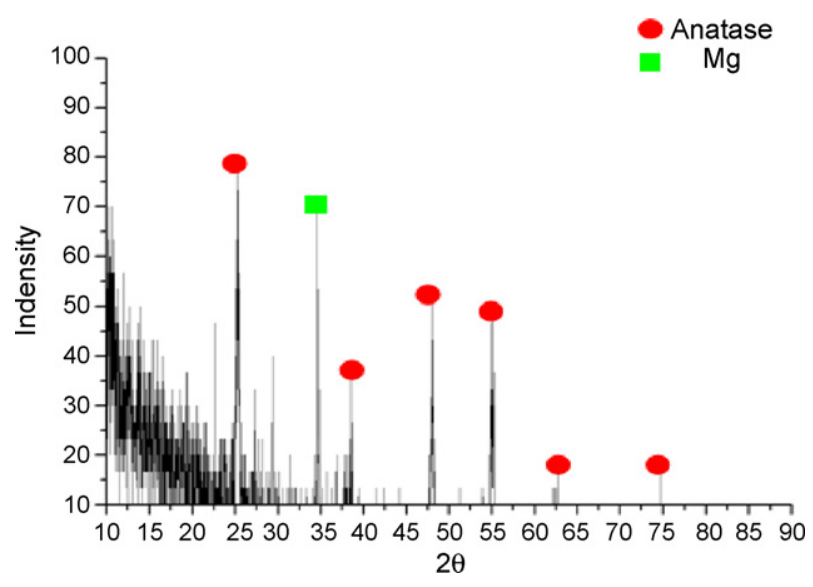

Fig. 1. X-ray diffraction spectrum for the deposited film.

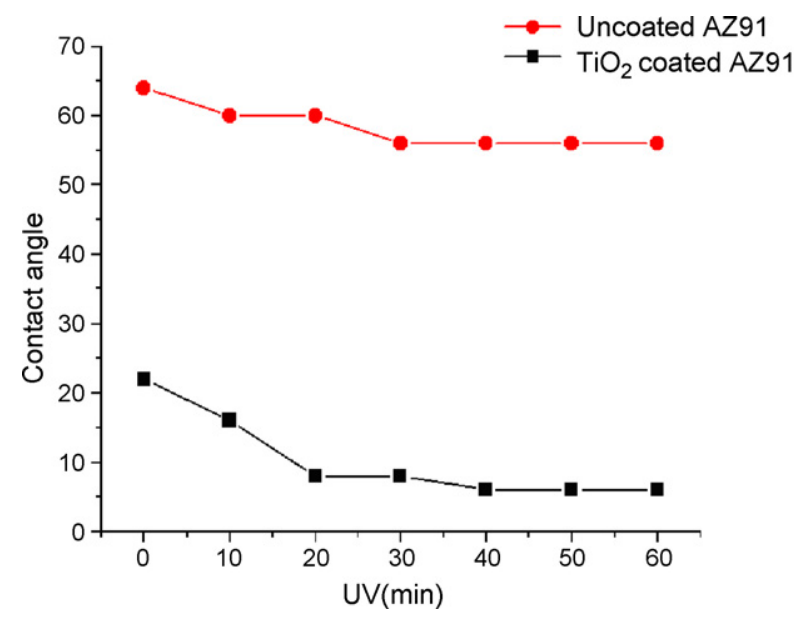

Fig. 2. Contact angle of uncoated and $\mathrm{TiO}_{2}$-coated AZ91 alloys as a function of UV exposure time.

ations as a function of UV exposure time for uncoated AZ91 substrates and AZ91 substrates deposited with a thin film of $\mathrm{TiO}_{2}$. Since the contact angle variations observed in this study are significant, the effect of surface roughness on the contact angles may be neglected. Uncoated AZ91 substrates exhibited very high contact angles, as high as $60^{\circ}$, even after UV exposure. On the other hand, the contact angles of $\mathrm{TiO}_{2}$-coated substrates dropped to less than $10^{\circ}$ after UV light exposure for more than 10 min, indicating a distinct hydrophilicity of $\mathrm{TiO}_{2}$-coated $\mathrm{AZ91}$ samples.

\subsection{Corrosion resistance test}

According to mixed potential theory, the corrosion current densities of cathode and anode are equal to each other when the intersecting potentials of anode and cathode polarization curves are the same. The corrosion current, corrosion current density, and corrosion potential can be obtained from the polarization curve [18].

Fig. 3 shows the potentiodynamic polarization curves of uncoated AZ91 sample and AZ91 sample deposited with photocatalytic thin films. The curves showed a corrosion potential of $-1.45 \mathrm{~V}$ for uncoated AZ91 substrates and $-1.26 \mathrm{~V}$ for the $\mathrm{TiO}_{2}$-deposited samples. Since higher corrosion potential means better corrosion resistance, the corrosion resistance of $\mathrm{TiO}_{2}$-deposited substrate is therefore better than that of uncoated AZ91 alloy. The corrosion current density of uncoated AZ91 alloy, however, was as low as $20.7 \mathrm{~mA} / \mathrm{cm}^{2}$, in contrast to the much higher $720 \mathrm{~mA} / \mathrm{cm}^{2}$ for $\mathrm{TiO}_{2}$-deposited AZ91 alloy. Moreover, observation of the surface structure after corrosion test showed that $\mathrm{TiO}_{2}$-deposited samples had corroded much more severely than did uncoated AZ91 alloy, as seen in Fig. 4. FE-SEM analysis on the surfaces of these samples revealed many pinholes on the $\mathrm{TiO}_{2}$-deposited substrates, exposing the AZ91-substrates beneath the thin film. The deposited film of $\mathrm{TiO}_{2}$ and pinhole areas of magnesium substrate formed a Galvanic cell effect [19], causing accelerated corrosion. 


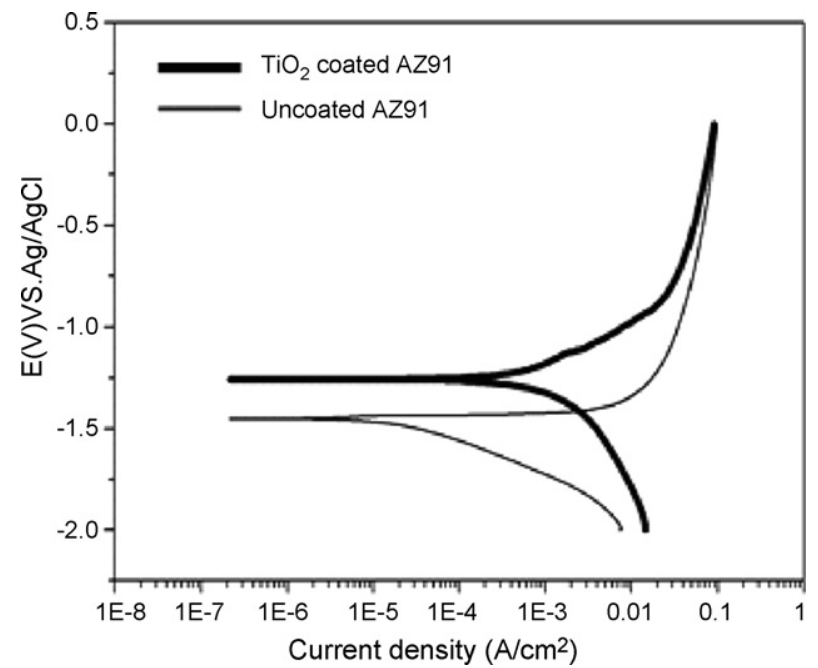

Fig. 3. Potentiodynamic polarization curves of uncoated and $\mathrm{TiO}_{2}$-coated $\mathrm{AZ} 91$ alloys.

\subsection{Microstructure and compositional analysis}

The microstructure of $\mathrm{TiO}_{2}$ photo-catalytic thin film shows many pinholes on the surface. From the quantitative image analysis, the pinholes present are approximately $10 \%$ of the coated area. Fig. 5 shows the high magnification FE-SEM microstructures. Clear images of the polygon-shaped anatase-structure can

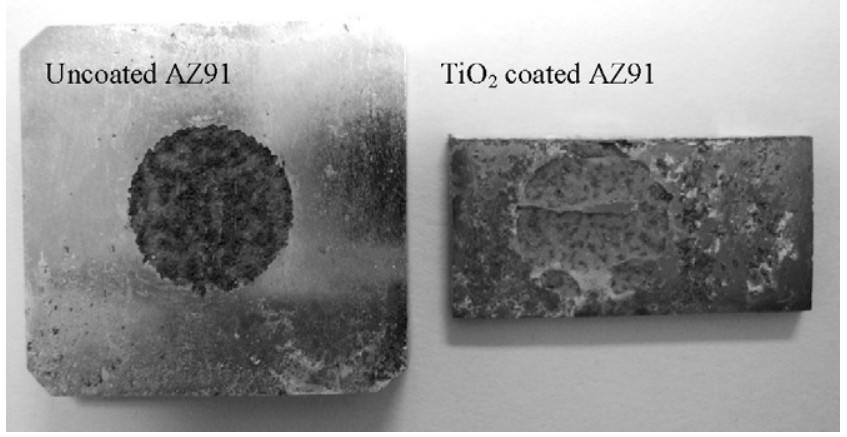

Fig. 4. Surface morphologies of uncoated and $\mathrm{TiO}_{2}$-coated $\mathrm{AZ91}$ alloy after corrosion test.

be identified in the pinhole-free region. The exposed parts of AZ91 substrate were visible inside the pinhole. Fig. 6 shows the presence of only $\mathrm{Ti}$ - and $\mathrm{O}$-peaks on $\mathrm{TiO}_{2}$ films. In contrast, pronounced $\mathrm{Mg}$-peaks, in addition to Ti- and O-peaks, were also found in the pinholes. It is speculated that the formation of pinhole was caused by the residual contaminants that remained on the surface because of insufficient cleaning of the AZ91 alloy substrate. Fig. 7 shows the FE-SEM microstructure of the crosssection of $\mathrm{TiO}_{2}$ films, about $1 \mu \mathrm{m}$ in thickness. The interface between the deposited film and the substrate was defect-free, indicating a good bonding between $\mathrm{TiO}_{2}$ films and AZ91 substrate. The EDS analysis of AZ91 substrate and $\mathrm{TiO}_{2}$ thin film (a)

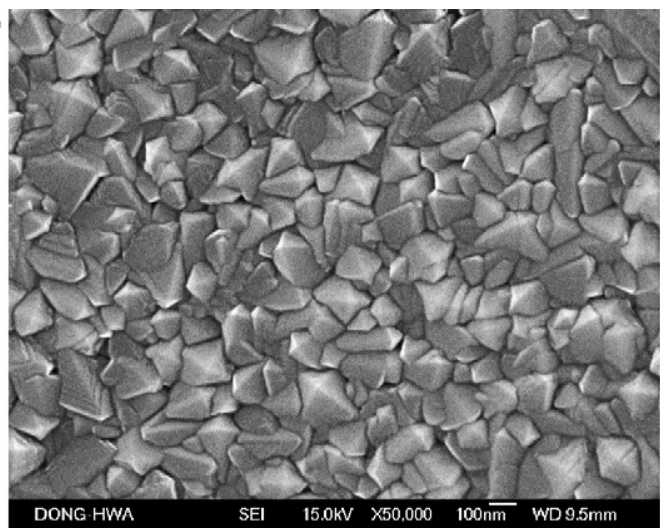

(b)

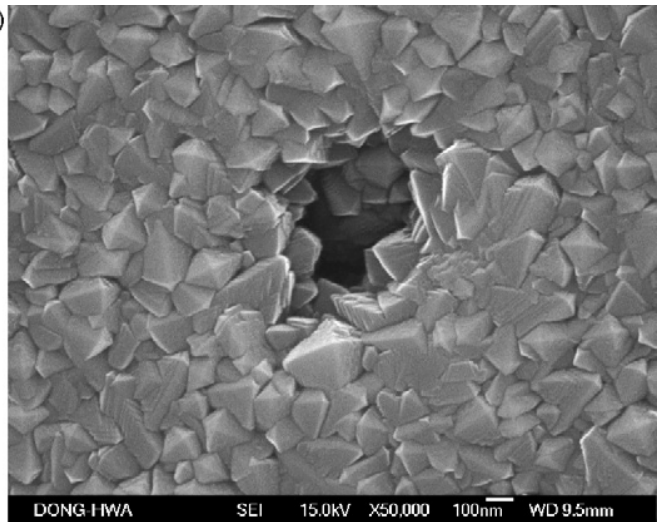

Fig. 5. FE-SEM surface images of $\mathrm{TiO}_{2}$-coated AZ91 alloy: (a) perfect coating region and (b) pinhole formation region.

(a)

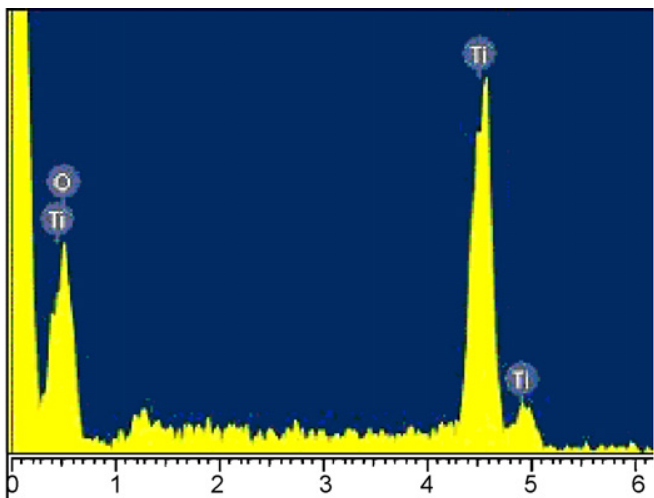

(b)

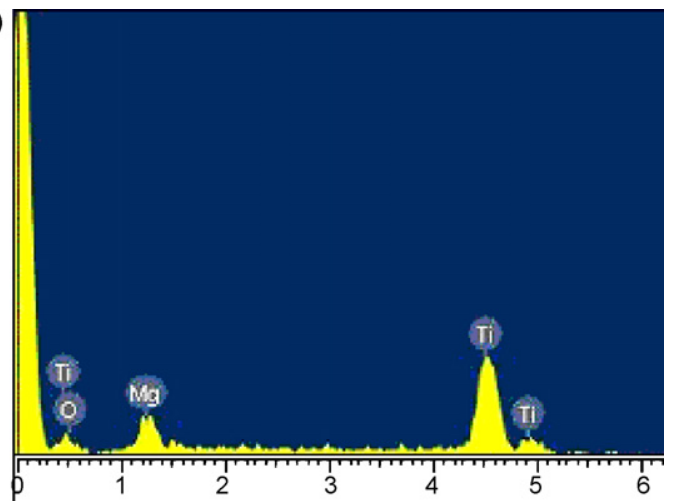

Fig. 6. EDS results of: (a) perfect coating region and (b) pinhole formation region. 


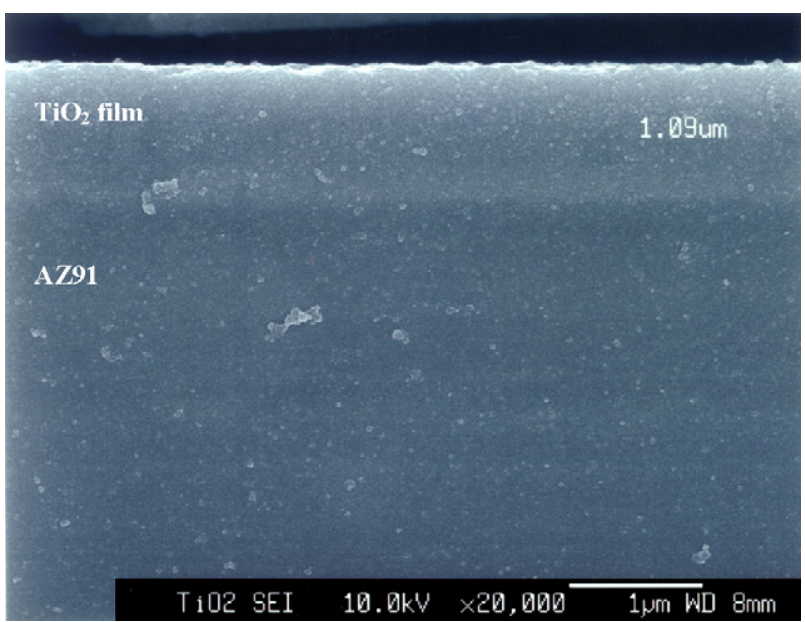

Fig. 7. FE-SEM cross section morphology of $\mathrm{TiO}_{2}$ coating.

(a)

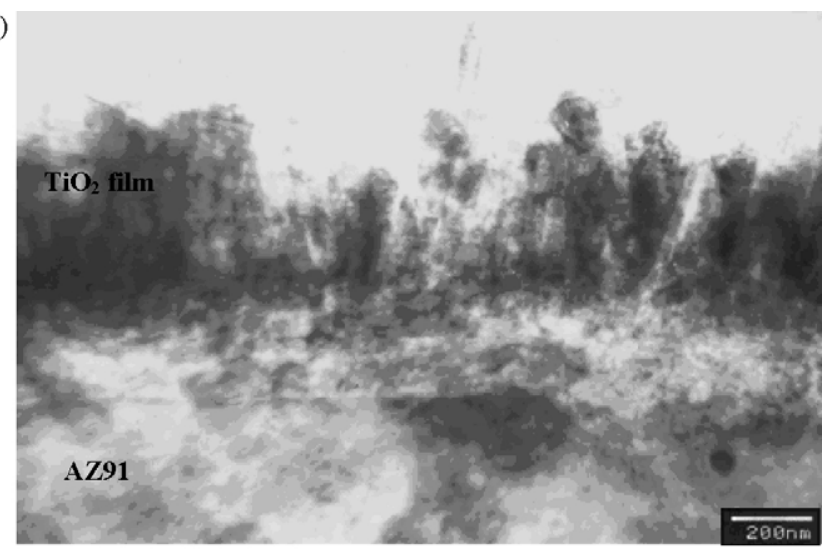

(b)

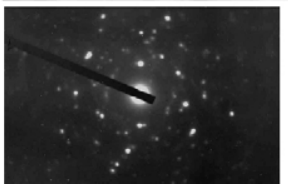

Fig. 8. (a) TEM cross section image of the $\mathrm{TiO}_{2}$ coating, and (b) SADP taken from the $\mathrm{TiO}_{2}$ film.

clearly shows the film composition to be $\mathrm{TiO}_{2}$. Fig. 8(a) shows the TEM image of the cross-section of $\mathrm{TiO}_{2}$ film. The difference in thickness observed between TEM and SEM images is a result of sample preparation method since, for TEM specimens, part of the thin film was ion milled away. The columnar-like structure of the $\mathrm{TiO}_{2}$ film indicated the crystallinity, as identified by SADP (selected area diffraction pattern) and shown in Fig. 8(b). The above image also showed that the deposited $\mathrm{TiO}_{2}$ thin film was not fully dense, with many pinholes on the surface. Under corrosive environments, oxygen molecules penetrated into AZ91 substrate and caused the accelerated corrosion. Prevention of pinhole formation is crucial in ensuring the protective function of $\mathrm{TiO}_{2}$ films.

\section{Conclusions}

The following conclusions can be summarized from the present study:

1. Anatase- $\mathrm{TiO}_{2}$ thin film could be deposited on AZ91 substrate using magnetron-sputtering technique.

2. AZ91 substrates, deposited with a thin film of $\mathrm{TiO}_{2}$, exhibited distinctive hydrophilic property, as illustrated by the contact angle measurements on samples exposed to UV light.

3. The corrosion potential of $\mathrm{TiO}_{2}$ thin film was higher than that of AZ91 Mg-alloy, suggesting the corrosion-resistant property of $\mathrm{TiO}_{2}$ thin films.

4. The poor overall corrosion resistance observed in the $\mathrm{TiO}_{2}$ deposited substrate was caused by the presence of pinholes on the deposited film, which, not fully dense, gave rise to Galvanic cell effect with accelerated corrosion. Preventing pinhole formation on $\mathrm{TiO}_{2}$ film will improve corrosion resistance and achieve photo-catalytic effect.

\section{Acknowledgment}

The authors would like to graciously acknowledge the financial support given from the National Science Council, Taiwan (contract: NSC94-2218-E-259-101).

\section{References}

[1] Y. Kojima, Mater. Trans. 42 (2001) 1154.

[2] S. Celotto, Acta Mater. 48 (2000) 1775.

[3] B.L. Mordilke, Mater. Sci. Eng. A: Struct. 302 (2001) 37.

[4] J.E. Gray, B. Luan, J Alloys Compd. 336 (2002) 88.

[5] Y. Zhang, C. Yan, F. Wang, H. Lou, C. Cao, Surf. Coat. Technol. 161 (2002) 36.

[6] T.F. Barton, J.A. Macculloch, P.N. Ross, United States Patent 6280598 (2001).

[7] O. Khaselev, D. Weiss, J. Yahalom, Corros. Sci. 43 (2001) 1295.

[8] E. Han, W. Zhou, D. Shan, W. Ke, Mater. Sci. Forum 419-422 (2003) 879.

[9] K. Mori, Z. Kang, J. Oravec, Y. Oishi, Mater. Sci. Forum 419-422 (2003) 889.

[10] A. Yamamoto, H. Tsubakino, Mater. Sci. Forum 419-422 (2003) 903.

[11] T.M. Yue, Y.P. Su, H.O. Yang, Mater. Lett. 61 (2007) 209.

[12] H. Altun, S. Sadri, Mater. Des. 27 (2006) 1174.

[13] D. Eliezer, P. Uzan, E. Aghion, Mater. Sci. Forum 419-422 (2003) 857.

[14] M.G. Fontana, N.D. Greene, Corrosion Engineering, second ed., McGrawHill, NY, USA, 1978, pp. 342-344.

[15] D.A. Jones, Principles and Prevention of Corrosion, second ed., Prentice Hall, NJ, USA, 1996, p. 96.

[16] Y. Hu, H.L. Tsai, C.L. Huang, Mater. Sci. Eng. A344 (2003) 209.

[17] N. Sakai, R. Wang, A. Fujishima, T. Watanabe, K. Hashimoto, Langmuir 14 (1998) 5918.

[18] H. Guo, M. An, S. Xu, H. Huo, Mater. Lett. 60 (2006) 1538.

[19] Y.Q. Wang, M.Y. Zheng, K. Wu, Mater. Lett. 59 (2005) 1727. 